\title{
Relation of IGF-I with subclinical cardiovascular markers including intima-media thickness, left ventricular mass index and NT-proBNP
}

Maximilian Eichner', Henri Wallaschofski ${ }^{1,2}$, Ulf Schminke ${ }^{3}$, Henry Völzke ${ }^{4,5}$, Marcus Dörr5,6, Stephan B Felix ${ }^{5,6}$, Matthias Nauck ${ }^{1,5}$ and Nele Friedrich ${ }^{1,5}$

${ }^{1}$ Institute of Clinical Chemistry and Laboratory Medicine, University Medicine Greifswald, Greifswald, Germany, ${ }^{2}$ Schwerpunktpraxis für Diabetes und Hormonerkrankungen, Erfurt, Germany, ${ }^{3}$ Department of Neurology, University Medicine Greifswald, Greifswald, Germany, ${ }^{4}$ Institute for Community Medicine, University Medicine Greifswald, Greifswald, Germany, ${ }^{5}$ DZHK (German Centre for Cardiovascular Research), Greifswald, Germany, and ${ }^{6}$ Department of Internal Medicine B, University Medicine Greifswald, Greifswald, Germany

\section{Correspondence} should be addressed to $\mathrm{N}$ Friedrich Email

nele.friedrich@med.uni-gr eifswald.de

\begin{abstract}
Objective: Several studies revealed relations between low or high insulin-like growth factor I (IGF-I) levels and risk of cardiovascular diseases or mortality, whereas the mechanisms behind these associations are still unknown.

Design: The study aimed to explore the relations between IGF-I and changes in surrogate markers of cardiovascular disease including carotid intima-media thickness (IMT), left ventricular mass index (LVMI) and N-terminal pro-brain natriuretic peptide (NT-proBNP).

Methods: Longitudinal data of the population-based cohort Study of Health in Pomerania (SHIP) were used. IMT was measured by ultrasonography and LVMI was determined based on echocardiography. IGF-I and IGF-binding protein-3 (IGFBP-3) levels were measured by chemiluminescent immunoassays and the IGF-I/IGFBP-3 ratio was calculated. Mixed linear regression models adjusted for known cardiovascular confounders were performed.

Results: Statistical analyses demonstrated relations between low baseline IGF-I levels (beta for $\triangle I M T$ per S.D. increase -0.044 (s.E. 0.012)) or IGF-I/IGFBP-3 ratio (beta $-0.045(0.012)$ ) and a long-term IMT increase. No associations between IGF-I, IGFBP-3 or IGF-I/IGFBP-3 ratio and changes in LVMI were detected. With respect to NT-proBNP sex-specific associations with IGF-I were found. In women, higher baseline IGF-I levels (beta for $\triangle$ NT-proBNP per S.D. increase 5.92 (2.2)) or IGF-I/IGFBP-3 ratio (beta 4.48 (2.2)) were related to an increase in NT-proBNP levels. Among men, U-shaped relations of baseline levels of IGF-I, IGFBP-3 and the IGF-I/IGFBP-3 ratio with an increase in NT-proBNP were found. Conclusions: The study detected significant relations between IGF-I and long-term changes in IMT and NT-proBNP but not LVMI. These findings argue for different effects of the IGF-I axis with respect to various cardiovascular entities.
\end{abstract}

\section{Introduction}

Insulin-like growth factor I (IGF-I), synthesized in the liver upon stimulation by growth hormone (GH), is mostly ligated as part of a complex consisting also of an acidlabile subunit (ALS) and mainly IGF-binding protein-3 (IGFBP-3) $(1,2)$. IGFBP-3 belongs to a group of IGFBPs that take over different functions including transport of IGF-I, prolonging the half-life time of IGF-I, blocking its biological activity or even functioning independently as another type of growth factor $(2,3,4)$. Beside its liver source, production and release of IGF-I takes place in

Published by Bioscientifica Ltd. 
further tissues including bone and cardiovascular cells (5) so that paracrine and autocrine actions are known (2).

IGF-I stimulates cell proliferation, differentiation and further anabolic effects (3). Moreover, IGF-I and IGFBP-3 affect the cardiovascular system and have been associated with cardiovascular diseases (CVD) and mortality (5, 6, $7,8,9,10$ ) but up to now, the exact mechanisms behind these effects are not completely understood. Nevertheless, heart and arteries are known for their sensitivity to IGF-I as well as for the secretion of IGF-I $(5,9,11)$. Indeed, cardiovascular alterations like increased arterial stiffness (12), endothelial dysfunction and an increased risk of CVD have been reported to be associated with an IGF-I excess in patients with acromegaly (9). Also among patients with GH deficiency, characterized by low IGF-I levels, cardiovascular changes including for example a reduction of cardiac mass or an impairment of cardiac function consequently lead to an increased cardiovascular morbidity and mortality risk (13).

However, studies $(6,7,8,14,15,16,17,18,19,20)$ independent of acromegaly and GH deficiency reported controversial findings regarding IGF-I or IGFBP-3-related effects on the cardiovascular system. On one side, lower IGF-I or IGFBP-3 levels were related to a higher ratio of total/HDL cholesterol as well as to an increased risk of ischemic stroke (8) which implies a role of the IGF-I/ IGFBP-3 system in genesis and progress of atherosclerosis (7). On the other side, the finding of no association between IGF-I or IGFBP-3 and left ventricular hypertrophy $(\mathrm{LVH})$ in a large population-based study (18) argues in opposite direction. In context of prospective studies investigating different cardiovascular outcomes $(6,16$, 17, 19, 20, 21, 22), Juul et al. (6) discovered that subjects with low IGF-I levels had an increased risk of incident ischemic heart disease which were confirmed with respect to lethal ischemic heart diseases in The Rancho Bernardo Study (17). Moreover, in the Framingham Heart Study, among elderly subjects lower IGF-I levels were related to an increased risk of developing heart failure (16) as well as ischemic stroke (22) with the latter only seen in subjects with diabetes. Similar results concerning the relation between lower IGF-I levels and the risk of heart failure were detected within the Cardiovascular Health Study (21), while a contrasting study related high levels of IGF-I with an elevated risk of chronic heart failure (20). Interestingly, Carlzon et al. (19) reported that low as well as high IGF-I levels were related to an elevated risk of incident cardiovascular events in elderly men.

Beside manifest diseases, IGF-I was investigated in relation to N-terminal pro-brain natriuretic peptide
(NT-proBNP), a guideline recommended prognostic biomarker that is used for diagnosing heart failure and monitoring its treatment $(23,24)$. NT-proBNP is produced by cardiac cells especially under stretching and created by enzymatic cutting of the pro-brain natriuretic peptide (BNP) $(25,26,27)$. Several population-based studies suggested NT-proBNP as predictor of cardiovascular events $(28,29)$ and mortality $(28,30)$. With regard to IGF-I and its potential relation to NT-proBNP, studies found conflicting results $(20,31,32)$. Andreassen et al. (31) did not detect any significant relation between IGF-I and NT-proBNP neither in patients with acromegaly nor GH deficiency. However, this study revealed significant lower NT-proBNP levels in subjects with untreated active acromegaly in comparison to treated inactive subjects or controls. Another study (32) found no essential differences in NT-proBNP levels among individuals who were recently diagnosed with acromegaly and controls. In contrast, a previous Danish cross-sectional study discovered that lower IGF-I levels were associated with higher NT-proBNP levels among subjects free of GH or IGF-I-related diseases (20).

Taken together, there is still a controversy concerning the long-term influence of IGF-I levels on the cardiovascular system in subjects without active acromegaly or GH deficiency. Therefore, the present study will focus on subclinical cardiovascular alteration as early markers of CVD and aims to investigate the relations between baseline IGF-I and IGFBP-3 levels and changes in carotid intima-media thickness (IMT) or left ventricular mass index (LVMI) as well as NT-proBNP during a 5-year follow-up period in a population-based setting.

\section{Subjects and methods}

\section{Study population}

The Study of Health in Pomerania (SHIP) is a populationbased cohort study conducted in West Pomerania, a region in northeast Germany $(33,34)$. The two-stage stratified cluster sampling was based on official data from population registries in the Federal State of Mecklenburg/ West Pomerania. Study subjects received a maximum of three written invitations, followed by repeated telephone calls and in-person contacts at home. The baseline examinations (SHIP-0) in the SHIP cohort were performed between 1997 and 2001 with a total of 4308 men and women aged 20-79 years (response rate 68.8\%). The first follow-up (SHIP-1) was performed between 2002 and 2006 with 3300 subjects being re-examined (response rate 
83.6\%). The second follow-up (SHIP-2) was performed between 2008 and 2012 with 2333 subjects being re-examined (response rate 62.9\%). The SHIP cohort study has been extensively studied and contributed data to more than 500 publications investigating various phenotypes, starting from the year 2000 (33). All participants provided written informed consent. The study conformed to the principles of the Declaration of Helsinki as reflected by an a priori approval of the Ethics Committee of the University of Greifswald.

In all three examination waves subjects with pacemaker or carotid artery stenosis (see below for methodology) were excluded $(n=264)$. Based on original outcome values (IMT, LVMI, NT-proBNP) or z-score values (IMT, LVMI) subjects with extreme values as well as missing values for outcome change, IGF-I, IGFBP-3 or confounder parameters were excluded. Therefore, the used study population varied between outcome and statistical model (Fig. 1 and Supplementary Fig. 1, see section on supplementary materials given at the end of this article).

\section{Interview and physical examination}

All participants were offered a large range of standardized medical examinations, blood sampling and an extensive computer-aided personal interview in SHIP-0 and SHIP-1. During the personal interview, information on sociodemographic characteristics, lifestyle and medical histories were collected. Smoking status was assessed by self-report and categorised into current, former and neversmokers. Participants were defined as physically inactive, if they reported less than $1 \mathrm{~h}$ of regular physical activity per week. Mean daily alcohol consumption was calculated using beverage-specific pure ethanol volume proportions (35). Waist circumference (WC) was measured to the nearest $0.1 \mathrm{~cm}$ using an inelastic tape midway between the lower rib margin and the iliac crest in the horizontal plane, with the subject standing comfortably with weight distributed evenly on both feet. After a resting period of at least 5 min, systolic and diastolic blood pressure were measured three times on the right arm of seated participants with an oscillometric digital blood pressure monitor (HEM-705CP, Omron Corporation, Tokyo, Japan). The interval between the readings was $3 \mathrm{~min}$. The mean of the second and third measurements was calculated.

\section{Laboratory measurements}

Non-fasting blood samples were drawn from the cubital vein in the supine position. The samples were analyzed immediately or stored at $-80^{\circ} \mathrm{C}$. Total cholesterol levels were photometrically measured in SHIP-0 (Hitachi 704, Roche AG) and enzymatically measured on a Dimension RxL automatic analyser (Siemens Healthcare Diagnostics) in SHIP-1. Glycated hemoglobin (HbA1c) concentrations were determined by HPLC (Bio-Rad Diamat) in SHIP-0 and SHIP-1. In both SHIP-0 and SHIP-1, serum IGF-I and IGFBP-3 concentrations were determined by automated two-site chemiluminescent immunoassays on the IDS-iSYS (Immunodiagnostic Systems) as previously described (36). According to the manufacturer, the limit of blank (LoB), limit of detection (LoD) and limit of quantitation (LoQ) were $1.9 \mathrm{ng} / \mathrm{mL}, 4.4 \mathrm{ng} / \mathrm{mL}$ and $8.8 \mathrm{ng} / \mathrm{mL}$ for the IGF-I assay as well as $30 \mathrm{ng} / \mathrm{mL}, 50 \mathrm{ng} / \mathrm{mL}$ and $80 \mathrm{ng} / \mathrm{mL}$ for the IGFBP-3 assay, respectively. For the IGF-I measurements, the coefficient of variance (CV) was 6.0\% and 5.0\% (high levels) as well as 9.8\% and 10.2\% (low levels) in SHIP-0 and SHIP-1, respectively. With respect to IGFBP-3, the CV was $7.9 \%$ and $9.2 \%$ (high levels) as well as $15.5 \%$ and $13.1 \%$ (low levels) in SHIP-0 and SHIP-1, respectively. Serum NT-proBNP were measured by standard methods (Dimension VISTA, Siemens Healthcare Diagnostics). The CV was 3.9\%, 3.8\% and 3.9\%\% (high levels) as well as $5.2 \%, 5.4 \%$ and 5.0\% (low levels) in SHIP-0, SHIP-1 and SHIP-2, respectively. All assays were performed according to the manufacturers' recommendations by skilled technical personnel.

\section{Echocardiography and ultrasound of the carotid arteries}

In SHIP-0 (only subjects $>45$ years), SHIP-1 and SHIP-2, two-dimensional and M-mode echocardiography was performed by certified physicians using a Vingmed CFM 800A system (GE Medical Systems). M-mode images of the left ventricle were recorded at papillary level. Left ventricular dimensions (interventricular septum thickness (IVS), posterior wall thickness (LVPW), and left ventricular end diastolic (LVDD) and systolic (LVDS) diameter) were measured using the leading edge convention. LVMI was calculated according to: $\mathrm{LVMI}=0.80 \times(1.04 \times((\mathrm{L}$ VDD + IVS + LVPW $\left.\left.)^{3}-\mathrm{LVDD}^{3}\right)\right)+0.60 /$ height $^{2.7} \quad(37, \quad 38)$. $\mathrm{LVH}$ was defined as a LVMI of $>48 \mathrm{~g} / \mathrm{m}^{2.7}$ in men and $>44$ $\mathrm{g} / \mathrm{m}^{2.7}$ in women (39).

The protocol of carotid ultrasound has been previously described (40). In SHIP-0 and SHIP-1 the examination of the extracranial carotid arteries was performed with B-mode ultrasonography using a $5 \mathrm{MHz}$ linear array transducer with an axial resolution of less than $0.5 \mathrm{~mm}$ and a high-resolution instrument (Diasonics VST Gateway, 
A

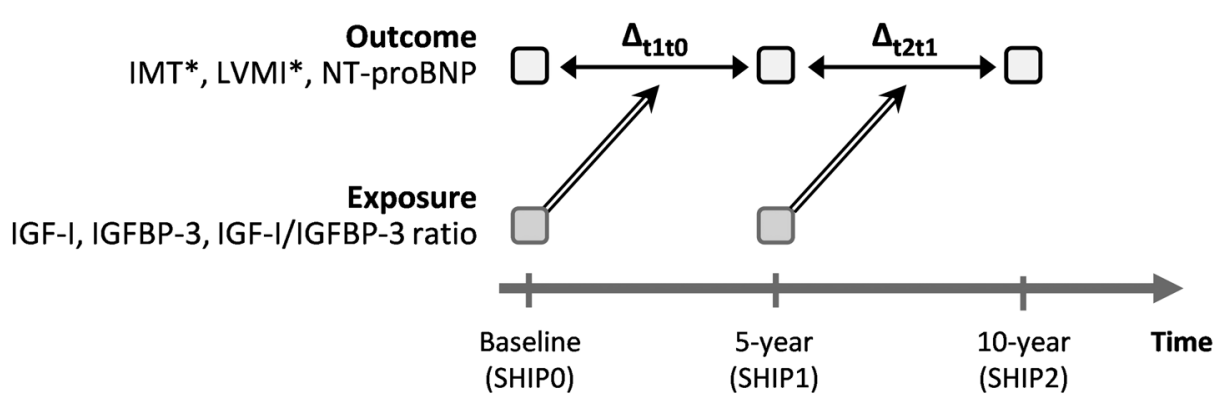

B

\section{$\Delta$ of outcomes based on original values}

Subjects with at least 2 examinations

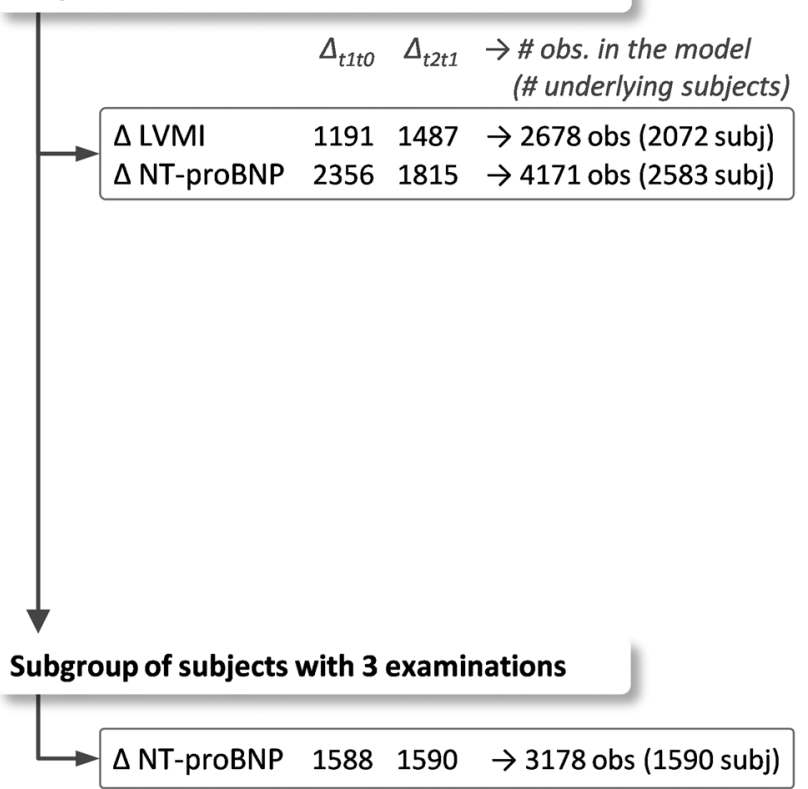

$\Delta$ of outcomes based on z-score ${ }_{\text {oll }}$ values

Subjects with at least 2 examinations

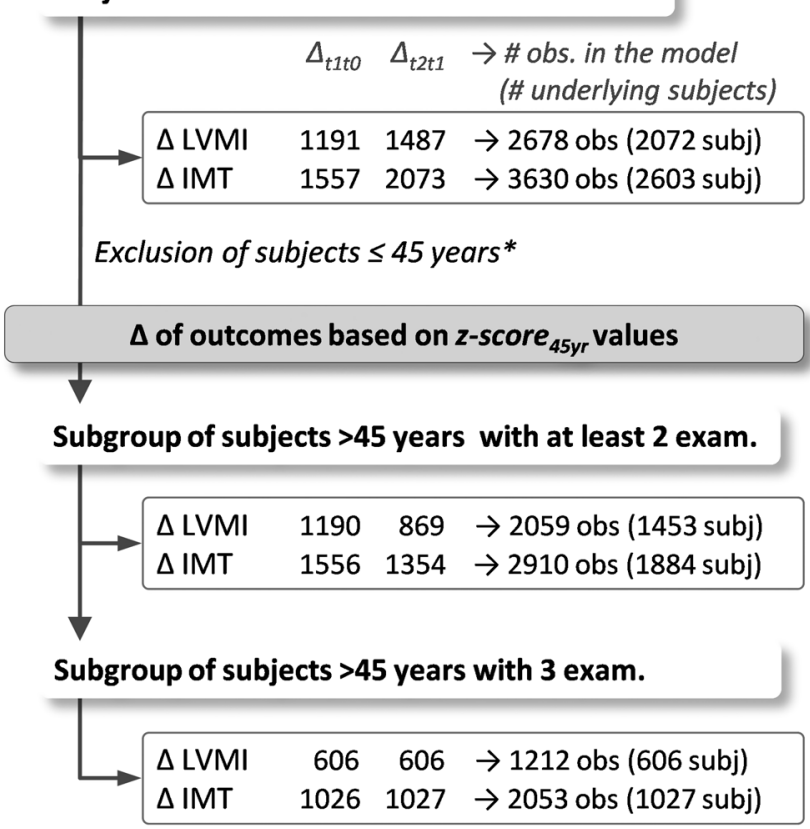

Figure 1

(A) Graphical chart of longitudinal analyses. (B) Flow diagram of analyses strategies. For mixed model analyses up to two observations (obs) per subjects (subj) were included in the models based on the 5-year changes between SHIP-1 and SHIP-0 ( $\Delta_{\mathrm{t} 1 \mathrm{t} 0}$ ) as well as SHIP-2 and SHIP-1 $\left(\Delta_{\mathrm{t} 2 \mathrm{t} 1}\right)$. IGF-I, insulin-like growth factor 1; IGFBP-3, IGF-binding protein; IMT, intima media thickness; LVMI, left ventricular mass index; NT-proBNP, N-terminal pro-brain natriuretic peptide; SHIP, Study of Health in Pomerania.

Santa Clara, USA). Doppler spectra and flow velocities were analyzed to determine internal carotid artery stenosis of at least $20 \%$ lumen narrowing according to NASCET criteria. The mean far-wall IMT was calculated from ten measurements taken manually in 1-mm steps from offline scans of the distal straight portion of both common carotid arteries. In SHIP-2 ultrasonography was performed using a linear array transducer with an operating frequency of $13 \mathrm{MHz}$ and a portable high-resolution instrument (vivid-i, GE Medical Systems). The mean far-wall IMT of the distal straight portion of both common carotid arteries was measured semi-automatically on screen using an edge tracking software, which calculates a mean value by averaging approximately 250 measurements at an arterial segment of $1 \mathrm{~cm}$ in length. The mean IMT averages all IMT measurements of the right and left common carotid arteries.

\section{Statistical analysis}

Continuous data are expressed as median (Q1, Q3) and categorical data as percentage. $\chi^{2}$ test (categorical 
data) or Mann-Whitney $U$ test (continuous data) were used for comparisons of men and women. Mixed linear models with random intercept were used to examine the longitudinal association between IGF-I, IGFBP-3 or the IGF-I/IGFBP-3 ratio and 5-year changes in IMT, LVMI or NT-proBNP over time using repeated measurements. In case of two examinations per person one 5-year change $\left(\Delta_{\mathrm{t} 1 t 0}\right.$ or $\left.\Delta_{\mathrm{t} 2 \mathrm{t} 1}\right)$ and in case of three examinations two 5-year changes $\left(\Delta_{\mathrm{t} 10}\right.$ and $\left.\Delta_{\mathrm{t} 211}\right)$ were used in the models (Fig. 1). The median follow-up time based on the NT-proBNP dataset (Fig. 1 and Supplementary Fig. 1) was 1962 days (Q1: 1835 days; Q3: 2135 days). Beside the original values to calculate the changes over time, with respect to IMT and LVMI different z-score calculations in the three examinations were used to obtain comparable measurements over all three time points (Fig. 2): (1) based on all subjects participating in the single examination with available data or (2) based only on subjects $>45$ years in the single examination with available data. The reason for the latter version is that the IMT and LVMI measurements were only performed in subjects $>45$ years in the baseline (SHIP-0) examination. For the IMT measurement a change in the methods occurred between the 5-year (SHIP-1) and 10-year (SHIP-2) follow-up resulting in non-comparable results as reflected in a decreasing mean IMT between the 5-year and 10-year follow-up (Fig. 2). Therefore, the use of z-score is required. Prior to the analyses, sex was tested as a potential effect modifier with respect to all three outcomes. Only for NT-proBNP significant interaction terms $(P<0.10)$ were found resulting in sexspecific analyses. However, due to the previous reported differences in the relations of IGF-I and cardiovascular outcomes $(18,41)$ sex-specific analyses regarding IMT and LVMI were also performed and the respective results are reported in the supplement. All models were adjusted for sex (only for IMT and LVMI), age, waist circumference, total cholesterol, HbA1c, systolic blood pressure and smoking. In the supplement we additionally report the results of two reduced adjustment sets. To account for possible non-linear associations restricted cubic splines with three knots were used. The three knots were prespecified located at the 5th, 50th, and 95th percentile as recommended by Stone and Koo (42) resulting in one component of the spline function: for example, IGF-I ${ }^{\mathrm{I}}$. Statistical analyses were performed using SAS, version 9.4 (SAS statistical software, version 9.4, SAS Institute, Inc.).

\section{Results}

\section{Baseline characteristics}

Baseline characteristics are presented in Table 1. Women were less often smokers and consumed less alcohol compared to men. Moreover, women showed a more healthy profile with respect to waist circumference, lipids and systolic blood pressure as well as hypertension and diabetes than men. While no sex differences in IGF-I levels were observed, IGFBP-3 levels were higher in women resulting in lower IGF-I/IGFBP-3 ratio values. With respect to cardiovascular parameters, women had higher NT-proBNP levels and lower LVMI and IMT values compared to men.

\section{Intima-media thickness and left ventricular mass}

With respect to IMT, over a 10-year follow-up period we observed an increase in IMT using z-score values as seen in Fig. 2. Mixed linear models adjusted for sex, age, waist circumference, smoking, total cholesterol, HbA1c as well as systolic blood pressure demonstrated significant associations of baseline IGF-I serum levels with changes
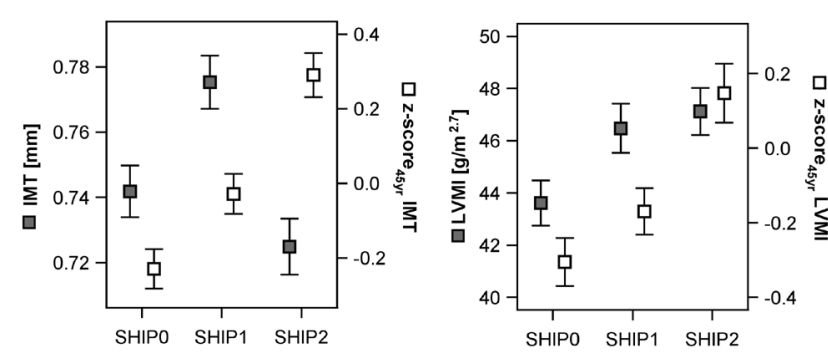

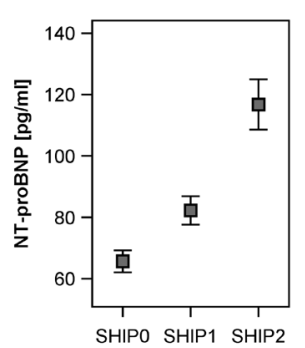

\section{Figure 2}

Mean with 95\% confidence interval of intima-media-thickness (IMT), left ventricular mass index (LVMI) or $\mathrm{N}$-terminal pro-brain natriuretic peptide (NT-proBNP) at baseline (SHIP-0), 5-year (SHIP-1) and 10-year (SHIP-2) follow-up. Only subjects with examination at all three time points were displayed. Data were shown as original values (grey) and/or z-score values (white). SHIP, Study of Health in Pomerania. 
Table 1 Baseline general characteristics of the study population by sex. Continuous data are expressed as median (interquartile range) and mean (S.E.); nominal data are given as percentages.

\begin{tabular}{l}
\hline \\
\hline Smoking \\
$\quad$ Never smoker \\
Former smoker \\
Current smoker \\
Hypertension \\
Diabetes \\
Age (years) \\
Alcohol consumption (g/day) \\
Waist circumference (cm) \\
Total cholesterol (mmol/L) \\
LDL cholesterol (mmol/L) \\
Systolic blood pressure (mmHG) \\
IGF-I (ng/mL) \\
IGFBP-3 (ng/mL) \\
IGF-I/IGFBP-3 ratio \\
IMT (mm)* \\
LVMI (g/m².7)* \\
NT-proBNP (pg/mL)*
\end{tabular}

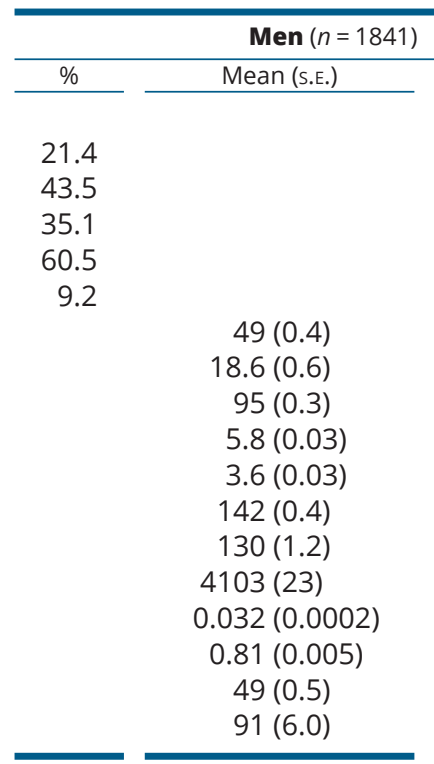

Median (IQR)

\begin{tabular}{|c|c|c|}
\hline \multicolumn{3}{|c|}{ Women $(n=1982)$} \\
\hline$\%$ & Mean (S.E.) & Median (IQR) \\
\hline \multicolumn{3}{|c|}{49.5} \\
\hline \multicolumn{3}{|c|}{23.0} \\
\hline \multicolumn{3}{|c|}{27.5} \\
\hline \multicolumn{3}{|c|}{39.7} \\
\hline \multicolumn{3}{|c|}{7.3} \\
\hline & $48(0.4)$ & $48(26)$ \\
\hline & $6.1(0.2)$ & $3.3(7.2)$ \\
\hline & $83(0.3)$ & $81(20)$ \\
\hline & $5.7(0.03)$ & $5.6(1.6)$ \\
\hline & $3.5(0.03)$ & $3.4(1.5)$ \\
\hline & $129(0.5)$ & $126(28)$ \\
\hline & $128(1.1)$ & $121(65)$ \\
\hline & $4298(20)$ & 4249 (1126) \\
\hline & $0.030(0.0002)$ & $0.028(0.012)$ \\
\hline & $0.74(0.004)$ & $0.72(0.18)$ \\
\hline & $46(0.4)$ & 44 (16) \\
\hline & $104(3.8)$ & $67(76)$ \\
\hline
\end{tabular}

*Varying numbers: IMT (men 1028; women 1054), LVMI (men 768; women 929), NT-proBNP (men 1640; women 1824).

IGF-I, insulin-like growth factor 1; IGFBP-3, IGF-binding protein-3; IMT, intima-media-thickness; LDL, low-density lipoprotein; LVMI, left ventricular mass index; NT-proBNP, N-terminal pro-brain natriuretic peptide.

in the IMT based on the z-score values (Table 2). These results were confirmed for the IGF-I/IGFBP-3 ratio. Lower baseline IGF-I or IGF-I/IGFBP-3 ratio levels were related to a higher increase in the IMT (Fig. 3). In subgroup analyses restricted to subjects $>45$ years with at least two examinations or three examinations, the associations were lost which might be mainly due to the reduced number of used observations. No associations between IGFBP-3 alone and changes in IMT became apparent (Table 2). Sexspecific analyses (Supplementary Table 1) confirmed the main finding of a relation between IGF-I and changes in the IMT. While the direction of the effect estimates was similar in men and women, the association itself was clearly stronger in women. In men, the estimate barely missed statistical significance $(P=0.07)$. In subgroup analyses, the associations disappeared in men similar to the overall results, whereas among women a trends toward associations of IGF-I $(P=0.10)$ or IGF-I/IGFBP-3 ratio $(P=0.12)$ with changes in IMT became apparent.

Considering LVMI, the expected increase over time was observed using the original as well as z-score values (Fig. 2). Mixed models did not detect any significant association between IGF-I, IGFBP-3 or IGF-I/IGFBP-3 ratio levels and changes in the LVMI over time in the overall (Fig. 3 and Table 2) or sex-specific analyses (Supplementary Table 1).
The results with respect to IMT and LVMI did not change using a reduced adjustment set (Supplementary Table 2).

\section{$\mathrm{N}$-terminal pro-brain natriuretic peptide}

Independent of sex, adjusted mixed models demonstrated significant associations between levels of IGF-I and changes in NT-proBNP levels (Fig. 3 and Table 3). In women, higher baseline IGF-I or IGF-I/IGFBP-3 ratio values were associated with an increase in NT-proBNP levels, whereas no significant association was detected between IGFBP-3 and changes in NT-proBNP. These results were also stable in the subpopulation of women $>45$ years participating in all three examinations. In men (Fig. 3 and Table 3), IGF-I and IGFBP-3 values showed significant U-shaped associations with changes in NT-proBNP levels. A similar trend was observed for the IGF-I/IGFBP-3 ratio, even though the estimates barely missed statistical significance. Taken together, low and high baseline values in IGF-I, IGFBP-3 or the IGF-I/IGFBP-3 ratio were linked to a higher increase in NT-proBNP levels. These findings were also seen in the subgroup of men with three examinations (Table 3) or using a reduced adjustment set (Supplementary Table 2).ixed linear regression model adjusted for age, waist circumference, total cholesterol, HbA1c, systolic blood 
pressure and smoking. IGF-I', IGFBP-3' and IGF-I/IGFBP$3^{\prime}$ represents the component of the spline function (see 'Subjects and methods' section).

\section{Discussion}

In the present population-based study, we discovered significant associations between IGF-I serum levels and changes in the IMT over time with lower IGF-I levels related to a higher increase in the IMT. Sex-specific analyses revealed a stronger association in women. Further analyses assessing the associations between the IGF-I/ IGFBP-3 system and NT-proBNP changes revealed positive associations in women and U-shaped associations in men. With respect to LVMI, no longitudinal relation to baseline IGF-I, IGFBP-3 or IGF-I/IGFBP-3 ratio levels were found.

\section{Intima-media thickness and left ventricular mass}

In a cross-sectional analysis, Hietaniemi et al. (43) detected sex-specific differences concerning the associations of IGF-I levels with IMT. While IGF-I levels were positively associated with IMT in women, an inverse and weaker association became apparent in men (43). With respect to free and therefore bioactive IGF-I levels, another crosssectional study discovered an inverse association to IMT in men aged 50 years (44). This finding is in accordance with a relation between lower free IGF-I levels and elevated thickness of the common carotid arteries in more than 400 senior men (45). However, also positive relations between IGF-I or IGFBP-3 levels and IMT among 300 Japanese men were discovered in a cross-sectional investigation (46).

Unfortunately, no longitudinal analyses were performed in these studies $(43,44,45,46)$. Previous population-based longitudinal studies were only performed with respect to manifest outcomes and detected relations of low IGF-I levels with cardiovascular alterations and incident diseases, namely an increased risk of ischemic heart disease (17), congestive heart failure (16, 21) and ischemic stroke (22). Even though these studies did not investigate cardiovascular markers like IMT, our findings are in concordance with their results $(16,17,21$, 22), as we showed that subjects with lower IGF-I levels had a more pronounced increase in IMT over time. However, our detected associations were more pronounced in women than in men, while the above-mentioned studies reported no notable sex differences in the associations between IGF-I and cardiovascular events $(16,17,21,22)$. Taken together these results suggest a protective effect of 

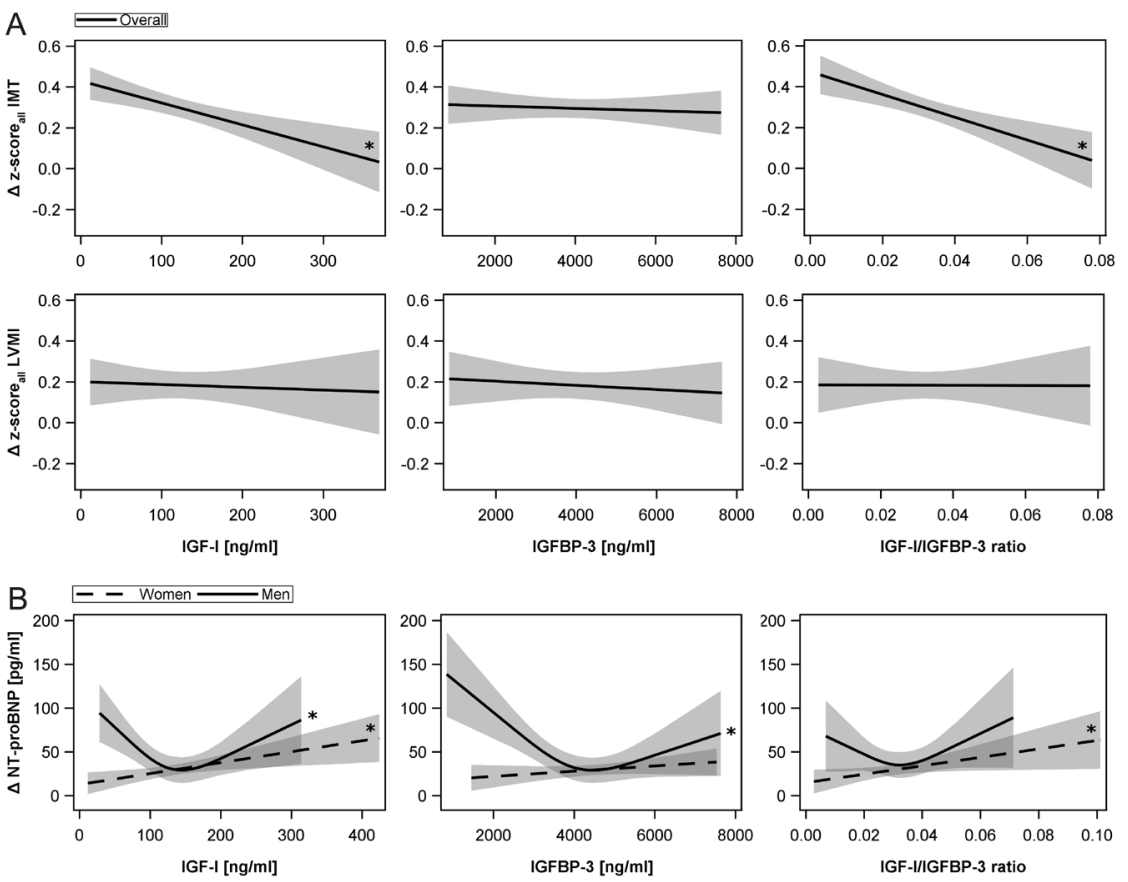

\section{Figure 3}

Associations between insulin-like growth factor I (IGF-I), IGF-binding protein-3 (IGFBP-3) ratio as well as IGF-I/IGFBP-3 ratio values and changes in $(A)$ intimamedia-thickness (IMT) or left ventricular mass index (LVMI) as well as (B) N-terminal pro-brain natriuretic peptide (NT-proBNP) for men and women. Gray areas indicate the $95 \%$ confidence interval. Mixed linear model adjusted for sex (only IMT and LVMI), age, waist circumference, total cholesterol, HbA1c, systolic blood pressure and smoking. In case of nonlinear associations restricted cubic splines with three knots were used resulting in the inclusion of one spline term in the model (for more details see 'Subjects and methods' section). The corresponding estimates are given in Tables 2 and 3. * Significant associations $(P<0.05$ for linear and if used spline term).
IGF-I in the development of an increased carotid IMT and therefore in the development of atherosclerosis. On the other side may lower IGF-I levels be accompanied with an increased risk of cardiovascular mortality. Focusing on that aspect, Friedrich et al. (41) discovered sex differences between IGF-I and cardiovascular mortality, namely a negative association in men, whereas in women no relation between IGF-I and mortality became apparent. In contrast, a Dutch study detected that both high and low IGF-I levels were significantly linked to increased cardiovascular mortality in 800 older subjects (47). The latter findings were confirmed by a meta-analysis regarding overall mortality as well as cardiovascular mortality (10). Despite these data, the link between IGF-I levels and mortality remains inconsistent as demonstrated in a more recent investigation from the Cardiovascular Health Study (21). It only revealed a relation between elevated IGF-I levels and increased cardiovascular mortality (21) but did

Table 3 Association between baseline IGF-I, IGFBP-3 or IGF-I/IGFBP-3 ratio and changes in NT-proBNP during a 5-year follow-up. Mixed linear regression model adjusted for age, waist circumference, total cholesterol, HbA1c, systolic blood pressure and smoking. IGF-I', IGFBP-3' and IGF-I/IGFBP-3' represents the component of the spline function (see 'Subjects and methods' section).

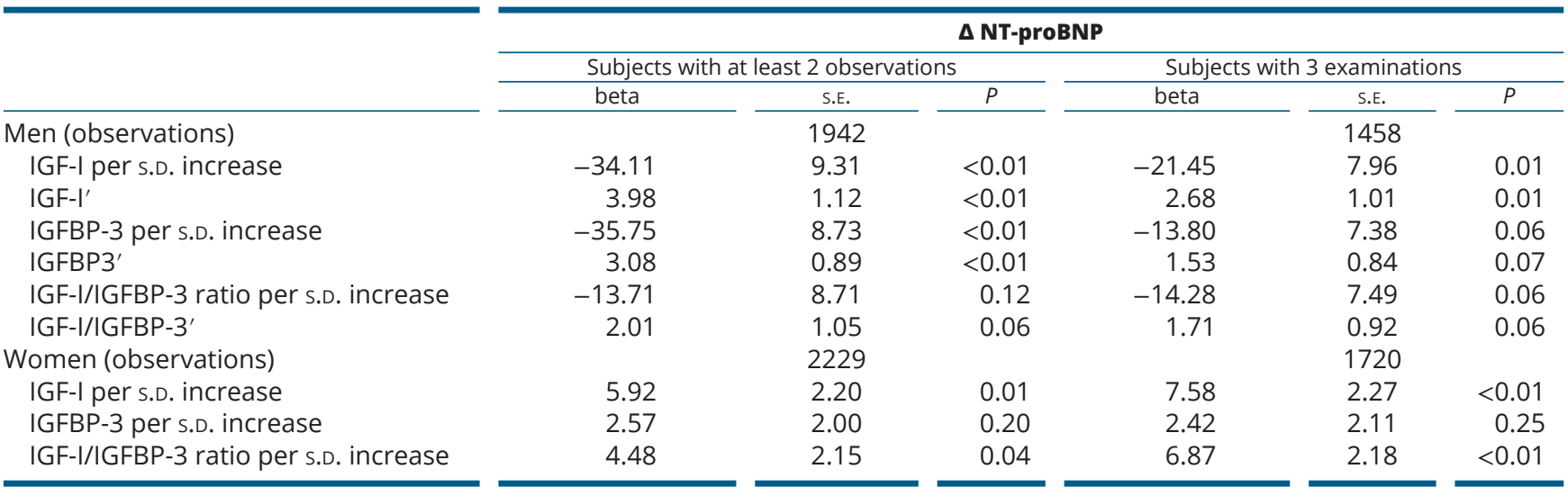

IGF-I, insulin-like growth factor 1; IGFBP-3, IGF-binding protein-3; NT-proBNP, N-terminal pro-brain natriuretic peptide. 
not confirm the reported U-shaped association (10). These conflicting results bring up the poorly answered question, whether baseline IGF-I values or trajectories of IGF-I levels should be considered, when IGF-I and its assumed link to mortality is researched (48).

Our results with respect to IMT confirm the previous findings of an association between low circulating IGF-I levels and CVD, by showing a stronger increase in IMT over time in subjects with low IGF-I, whereas the adverse effects of high levels on cardiovascular health could not be supported. It is sufficiently known that IGF-I levels decrease with age $(49,50)$ and that atherosclerosis is more common in older individuals, however, regarding a potential connection only little is known up to now. In 2007, Thum et al. (49) discovered that the GH-induced IGF-I increase leads to a positive effect on the number as well as on the function of endothelial progenitor cells that may counteract the age-related decrease in the number of endothelial progenitor cells. The authors concluded, also on the basis of the finding that individuals with reduced endothelial progenitor cells have a higher incidence of atherosclerotic events like unstable angina, cardiovascular death or ischemic stroke (51), that the described link between IGF-I and endothelial progenitor cells may represent a possible link between cardiovascular events and low IGF-I levels (49). Interestingly, acromegaly patients showed no age-related declines in endothelial progenitor cells, but had reduced circulating endothelial progenitor cells numbers with the highest reduction in patients with active acromegaly compared to healthy controls (52). This might be one explanation for the increased cardiovascular risk among acromegaly patients $(9,53)$. Moreover, treatment of acromegaly leads to an increase in endothelial progenitor cells. In addition, a recent review discussed IGF-I induced NO release from endothelial cells as mediator of vascular IGF-I effects (54). Taken together, our study associated lower IGF-I baseline levels to a higher increase of the IMT in both sexes and is in accordance with prior longitudinal studies $(16,17$, 22) that demonstrated a protective effect of IGF-I on the cardiovascular system, although sex differences became obvious which need to be further investigated.

Considering IGF-I levels and their relation to changes in LVMI over time, we found no association in the present study. These findings confirm the previous reported lack of a cross-sectional association in the same study population (18). On the contrary, the heart is well-known as an IGF-I responsive organ (55) and an older study reported insulin as well as IGF-I to possess determining features toward the LVM (56). As this previous study is based on a highly selective population of 101 never-treated nondiabetic subjects with essential hypertension the comparability between the studies is, however, limited. In conclusion, the present study did not identify associations of IGF-I to LVMI, although the heart responsiveness for IGF-I is well known.

\section{N-terminal pro-brain natriuretic peptide}

To our knowledge, this is the first large study investigating the relation between IGF-I and changes in NT-proBNP over time in a population-based setting. A previous Danish cross-sectional study found an inverse association between IGF-I levels and NT-proBNP (20) and is in concordance with findings in acromegaly showing that patients with an active disease had lower levels of NT-proBNP (57). Another study (58) focused on ethnical differences and confirmed an inverse association between IGF-I and NT-proBNP as well, but only in white and not in black individuals. Interestingly, Krim et al. (59) detected ethnical differences concerning the levels of natriuretic peptide with the result that black and also Asian individuals had significantly higher levels of BNP compared to Hispanic or white individuals. In the present study, we observed positive associations between baseline IGF-I or IGF-I/IGFBP-3 ratio and an increase of NT-proBNP levels in women as well as a significant U-shaped association between IGF-I and NT-proBNP levels in men. These findings are partly in conflict to the above-mentioned cross-sectional studies. Reasons for the discrepancies might be the investigated populations, the design of the studies (cross-sectional versus longitudinal) and the number of investigated subjects with our study being the largest with over 4000 subjects. Interestingly, in the present study clear sex differences in the association between IGF-I and NT-proBNP became visible. Up to now, only small evidence exists with respect to sex differences in NT-proBNP levels. Regarding natriuretic peptide, a recent review (60) discussed sex hormones as possible explanation for differences in NT-proBNP levels between men and women. Furthermore, a study by Wang et al. (61) detected female sex as one leading predictor for higher circulating levels of natriuretic peptide. In fact, it is not surprising that sex differences were detected in our study, as such are well known from previous studies assessing IGF-I and its potential relation to various, especially cardiovascular outcomes $(41,43)$. In addition, NT-proBNP (60) and more general natriuretic peptide (61) were discussed to be sex-specific. However, these sex differences need to be further explored to understand 
the observed interaction and consequently the different association patterns in women and men.

\section{Strength and limitations}

The present study is one of the largest or even the first study to investigate the impact of IGF-I and IGFBP-3 on changes in subclinical cardiovascular alterations in a population-based longitudinal setting. The large number of used observations as well as sex-specific analyses and use of a broad range of confounders represent the strength of the study. Limitations arise from the change in methods to determine the IMT or LVMI in the baseline as well as follow-up examinations. To overcome this limitation z-scores were used. External validation in a populationbased setting is necessary to determine generalizability of the present findings.

\section{Conclusion}

To the best of our knowledge, this study is the first to investigate and detect associations between IGF-I and changes in IMT and NT-proBNP in a population-based setting. Lower baseline IGF-I levels were linked to a higher increase in the IMT and NT-proBNP over 5 years in a population-based setting. Furthermore, in men, high baseline IGF-I levels were related to an increase in NT-proBNP. Therefore, we confirmed and extended the current knowledge on low IGF-I levels and their impact on the cardiovascular system. Moreover, the found U-shaped association between IGF-I and NT-proBNP might be one possible explanation for the detected U-shaped relation of IGF-I with cardiovascular mortality in a recent metaanalysis (10).

\section{Supplementary materials}

This is linked to the online version of the paper at https://doi.org/10.1530/ EJE-19-0470.

\section{Declaration of interest}

The authors declare that there is no conflict of interest that could be perceived as prejudicing the impartiality of this study.

\section{Funding}

This work was funded by grants from the German Federal Ministry of Education and Research (BMBF, Grants 01ZZ0403, 01ZZ0103, 01GI0883), the Ministry for Education, Research and Cultural Affairs as well as the Ministry of Social Affairs of the Federal State of Mecklenburg-West Pomerania. This work is also part of the research project Greifswald Approach to Individualized Medicine (GANI_MED). The GANI_MED consortium is funded by the Federal Ministry of Education and Research and the Ministry of Cultural Affairs of the Federal State of MecklenburgWest Pomerania (03IS2061A).

\section{References}

1 Leong SR, Baxter RC, Camerato T, Dai J \& Wood WI. Structure and functional expression of the acid-labile subunit of the insulin-like growth factor-binding protein complex. Molecular Endocrinology 1992 6 870-876. (https://doi.org/10.1210/mend.6.6.1379671)

2 Juul A. Serum levels of insulin-like growth factor I and its binding proteins in health and disease. Growth Hormone and IGF Research 200313 113-170. (https://doi.org/10.1016/s1096-6374(03)00038-8)

3 Jones JI \& Clemmons DR. Insulin-like growth factors and their binding proteins: biological actions. Endocrine Reviews 199516 3-34. (https://doi.org/10.1210/edrv-16-1-3)

4 Mohan S \& Baylink DJ. IGF-binding proteins are multifunctional and act via IGF-dependent and -independent mechanisms. Journal of Endocrinology 2002175 19-31. (https://doi.org/10.1677/ joe.0.1750019)

5 Bayes-Genis A, Conover CA \& Schwartz RS. The insulin-like growth factor axis: a review of atherosclerosis and restenosis. Circulation Research 200086 125-130. (https://doi.org/10.1161/01.res.86.2.125)

6 Juul A, Scheike T, Davidsen M, Gyllenborg J \& Jorgensen T. Low serum insulin-like growth factor I is associated with increased risk of ischemic heart disease: a population-based case-control study. Circulation 2002106 939-944. (https://doi.org/10.1161/01. cir.0000027563.44593.cc)

7 Colao A, Spiezia S, Di Somma C, Pivonello R, Marzullo P, Rota F, Musella T, Auriemma RS, De Martino MC \& Lombardi G. Circulating insulin-like growth factor-I levels are correlated with the atherosclerotic profile in healthy subjects independently of age. Journal of Endocrinological Investigation 200528 440-448. (https://doi. org/10.1007/bf03347225)

8 Johnsen SP, Hundborg HH, Sorensen HT, Orskov H, Tjonneland A, Overvad K \& Jorgensen JO. Insulin-like growth factor (IGF) I, -II, and IGF binding protein-3 and risk of ischemic stroke. Journal of Clinical Endocrinology and Metabolism 200590 5937-5941. (https://doi. org/10.1210/jc.2004-2088)

9 Colao A, Ferone D, Marzullo P \& Lombardi G. Systemic complications of acromegaly: epidemiology, pathogenesis, and management. Endocrine Reviews 200425 102-152. (https://doi. org/10.1210/er.2002-0022)

10 Burgers AM, Biermasz NR, Schoones JW, Pereira AM, Renehan AG, Zwahlen M, Egger M \& Dekkers OM. Meta-analysis and doseresponse metaregression: circulating insulin-like growth factor I (IGF-I) and mortality. Journal of Clinical Endocrinology and Metabolism 201196 2912-2920. (https://doi.org/10.1210/jc.2011-1377)

11 Sowers JR. Insulin and insulin-like growth factor in normal and pathological cardiovascular physiology. Hypertension 199729 691-699. (https://doi.org/10.1161/01.hyp.29.3.691)

12 Paisley AN, Banerjee M, Rezai M, Schofield RE, Balakrishnannair S, Herbert A, Lawrance JA, Trainer PJ \& Cruickshank JK. Changes in arterial stiffness but not carotid intimal thickness in acromegaly. Journal of Clinical Endocrinology and Metabolism 201196 1486-1492. (https://doi.org/10.1210/jc.2010-2225)

13 Lombardi G, Di Somma C, Grasso LF, Savanelli MC, Colao A \& Pivonello R. The cardiovascular system in growth hormone excess and growth hormone deficiency. Journal of Endocrinological Investigation 201235 1021-1029. (https://doi.org/10.3275/8717)

14 Ito H, Hiroe M, Hirata Y, Tsujino M, Adachi S, Shichiri M, Koike A, Nogami A \& Marumo F. Insulin-like growth factor-I induces hypertrophy with enhanced expression of muscle specific genes in cultured rat cardiomyocytes. Circulation 199387 1715-1721. (https:// doi.org/10.1161/01.cir.87.5.1715) 
15 Donohue TJ, Dworkin LD, Lango MN, Fliegner K, Lango RP, Benstein JA, Slater WR \& Catanese VM. Induction of myocardial insulin-like growth factor-I gene expression in left ventricular hypertrophy. Circulation 199489 799-809. (https://doi. org/10.1161/01.cir.89.2.799)

16 Vasan RS, Sullivan LM, D'Agostino RB, Roubenoff R, Harris T, Sawyer DB, Levy D \& Wilson PW. Serum insulin-like growth factor I and risk for heart failure in elderly individuals without a previous myocardial infarction: the Framingham Heart Study. Annals of Internal Medicine 2003139 642-648. (https://doi.org/10.7326/00034819-139-8-200310210-00007)

17 Laughlin GA, Barrett-Connor E, Criqui MH \& Kritz-Silverstein D. The prospective association of serum insulin-like growth factor I (IGF-I) and IGF-binding protein-1 levels with all cause and cardiovascular disease mortality in older adults: the Rancho Bernardo Study. Journal of Clinical Endocrinology and Metabolism 200489 114-120. (https:// doi.org/10.1210/jc.2003-030967)

18 Friedrich N, Aumann N, Dörr M, Felix SB, Nauck M, Wallaschofski H \& Völzke H. Lack of association between insulin-like growth factor-1 or insulin-like growth factor-binding protein-3 and left ventricular hypertrophy: results of the Study of Health in Pomerania. Journal of Hypertension 201028 856-864. (https://doi.org/10.1097/ HJH.0b013e328336274a)

19 Carlzon D, Svensson J, Petzold M, Karlsson MK, Ljunggren Ö, Tivesten A, Mellstrom D \& Ohlsson C. Both low and high serum IGF-1 levels associate with increased risk of cardiovascular events in elderly men. Journal of Clinical Endocrinology and Metabolism 201499 E2308-E2316. (https://doi.org/10.1210/jc.2014-1575)

20 Andreassen M, Raymond I, Kistorp C, Hildebrandt P, Faber J $\&$ Kristensen LØ. IGF1 as predictor of all cause mortality and cardiovascular disease in an elderly population. European Journal of Endocrinology 2009160 25-31. (https://doi.org/10.1530/EJE-08-0452)

21 Kaplan RC, Strizich G, Aneke-Nash C, Dominguez-Islas C, Buzkova P, Strickler H, Rohan T, Pollak M, Kuller L, Kizer JR et al. Insulinlike growth factor binding protein-1 and ghrelin predict health outcomes among older adults: cardiovascular health study cohort. Journal of Clinical Endocrinology and Metabolism 2017102 267-278. (https://doi. org/10.1210/jc.2016-2779)

22 Saber H, Himali JJ, Beiser AS, Shoamanesh A, Pikula A, Roubenoff R, Romero JR, Kase CS, Vasan RS \& Seshadri S. Serum insulin-like growth factor 1 and the risk of ischemic stroke: the Framingham study. Stroke 201748 1760-1765. (https://doi.org/10.1161/ STROKEAHA.116.016563)

23 Yancy CW, Jessup M, Bozkurt B, Butler J, Casey Jr DE, Drazner MH, Fonarow GC, Geraci SA, Horwich T, Januzzi JL et al. 2013 ACCF/ AHA guideline for the management of heart failure: a report of the American College of Cardiology Foundation/American Heart Association Task Force on Practice Guidelines. Journal of the American College of Cardiology 201362 e147-e239. (https://doi.org/10.1016/j. jacc.2013.05.019)

24 Francis GS, Felker GM \& Tang WH. A test in context: critical evaluation of natriuretic peptide testing in heart failure. Journal of the American College of Cardiology 201667 330-337. (https://doi. org/10.1016/j.jacc.2015.10.073)

25 Hunt PJ, Yandle TG, Nicholls MG, Richards AM \& Espiner EA. The amino-terminal portion of pro-brain natriuretic peptide (Pro-BNP) circulates in human plasma. Biochemical and Biophysical Research Communications 1995214 1175-1183. (https://doi.org/10.1006/ bbrc.1995.2410)

26 Hall C. Essential biochemistry and physiology of (NT-pro)BNP. European Journal of Heart Failure 20046 257-260. (https://doi. org/10.1016/j.ejheart.2003.12.015)

27 Hall C. NT-ProBNP: the mechanism behind the marker. Journal of Cardiac Failure 200511 S81-S83. (https://doi.org/10.1016/j. cardfail.2005.04.019)
28 Kistorp C, Raymond I, Pedersen F, Gustafsson F, Faber J \& Hildebrandt P. N-terminal pro-brain natriuretic peptide, C-reactive protein, and urinary albumin levels as predictors of mortality and cardiovascular events in older adults. JAMA 2005293 1609-1616. (https://doi.org/10.1001/jama.293.13.1609)

29 Olsen MH, Hansen TW, Christensen MK, Gustafsson F, Rasmussen S, Wachtell K, Ibsen H, Torp-Pedersen C \& Hildebrandt PR. N-terminal pro-brain natriuretic peptide, but not high sensitivity $\mathrm{C}$-reactive protein, improves cardiovascular risk prediction in the general population. European Heart Journal 200728 1374-1381. (https://doi. org/10.1093/eurheartj/ehl448)

30 Daniels LB, Laughlin GA, Clopton P, Maisel AS \& Barrett-Connor E. Minimally elevated cardiac troponin $\mathrm{T}$ and elevated $\mathrm{N}$-terminal pro-B-type natriuretic peptide predict mortality in older adults: results from the Rancho Bernardo Study. Journal of the American College of Cardiology 200852 450-459. (https://doi.org/10.1016/j. jacc.2008.04.033)

31 Andreassen M, Faber J, Vestergaard H, Kistorp C \& Kristensen LØ. $\mathrm{N}$-terminal pro-B-type natriuretic peptide in patients with growth hormone disturbances. Clinical Endocrinology 200766 619-625. (https://doi.org/10.1111/j.1365-2265.2007.02782.x)

32 Arikan S, Bahceci M, Tuzcu A \& Gokalp D. N-terminal pro-brain natriuretic peptide in newly diagnosed acromegaly. Journal of Endocrinological Investigation 201033 571-575. (https://doi. org/10.1007/BF03346650)

33 John U, Greiner B, Hensel E, Ludemann J, Piek M, Sauer S, Adam C, Born G, Alte D, Greiser E et al. Study of Health in Pomerania (SHIP): a health examination survey in an east German region: objectives and design. Soz Praventivmed 200146 186-194. (https://doi.org/10.1007/ bf01324255)

34 Völzke H, Alte D, Schmidt CO, Radke D, Lorbeer R, Friedrich N, Aumann N, Lau K, Piontek M, Born G et al. Cohort profile: the study of health in Pomerania. International Journal of Epidemiology 201140 294-307. (https://doi.org/10.1093/ije/dyp394)

35 Alte D, Luedemann J, Rose HJ \& John U. Laboratory markers carbohydrate-deficient transferrin, gamma-glutamyltransferase, and mean corpuscular volume are not useful as screening tools for high-risk drinking in the general population: results from the Study of Health in Pomerania (SHIP). Alcoholism, Clinical and Experimental Research 200428 931-940. (https://doi.org/10.1097/01. alc.0000128383.34605.16)

36 Müller C, Wallaschofski H, Brabant G, Wahnschaffe U, Samietz S, Nauck M \& Friedrich N. The association between IGF-I/IGFBP-3 and subclinical end points: epidemiology faces the limits. Journal of Clinical Endocrinology and Metabolism 201499 2804-2812. (https:// doi.org/10.1210/jc.2013-3746)

37 Devereux RB, Alonso DR, Lutas EM, Gottlieb GJ, Campo E, Sachs I \& Reichek N. Echocardiographic assessment of left ventricular hypertrophy: comparison to necropsy findings. American Journal of Cardiology 198657 450-458. (https://doi.org/10.1016/00029149(86)90771-x)

38 Lang RM, Bierig M, Devereux RB, Flachskampf FA, Foster E, Pellikka PA, Picard MH, Roman MJ, Seward J, Shanewise JS et al. Recommendations for chamber quantification: a report from the American Society of Echocardiography's Guidelines and Standards Committee and the Chamber Quantification Writing Group, developed in conjunction with the European Association of Echocardiography, a branch of the European Society of Cardiology. Journal of the American Society of Echocardiography 200518 1440-1463. (https://doi.org/10.1016/j.echo.2005.10.005)

39 Abs R, Bengtsson BA, Hernberg-Stâhl E, Monson JP, Tauber JP, Wilton P \& Wüster C. GH replacement in 1034 growth hormone deficient hypopituitary adults: demographic and clinical characteristics, dosing and safety. Clinical Endocrinology 199950 703-713. (https://doi.org/10.1046/j.1365-2265.1999.00695.x) 
40 Luedemann J, Schminke U, Berger K, Piek M, Willich SN, Doring A, John U \& Kessler C. Association between behavior-dependent cardiovascular risk factors and asymptomatic carotid atherosclerosis in a general population. Stroke 200233 2929-2935. (https://doi. org/10.1161/01.str.0000038422.57919.7f)

41 Friedrich N, Haring R, Nauck M, Lüdemann J, Rosskopf D, SpilckeLiss E, Felix SB, Dörr M, Brabant G, Völzke H et al. Mortality and serum insulin-like growth factor (IGF)-I and IGF binding protein 3 concentrations. Journal of Clinical Endocrinology and Metabolism 2009 94 1732-1739. (https://doi.org/10.1210/jc.2008-2138)

42 Hattori N. Expression, regulation and biological actions of growth hormone (GH) and ghrelin in the immune system. Growth Hormone and IGF Research 200919 187-197. (https://doi.org/10.1016/j. ghir.2008.12.001)

43 Hietaniemi M, Poykko SM, Ukkola O, Paivansalo M \& Antero Kesaniemi Y. IGF-I concentrations are positively associated with carotid artery atherosclerosis in women. Annals of Medicine 200537 373-382. (https://doi.org/10.1080/07853890510011967)

44 Boquist S, Ruotolo G, Skoglund-Andersson C, Tang R, Bjorkegren J, Bond MG, de Faire U, Brismar K \& Hamsten A. Correlation of serum IGF-I and IGFBP-1 and -3 to cardiovascular risk indicators and early carotid atherosclerosis in healthy middle-aged men. Clinical Endocrinology 200868 51-58. (https://doi.org/10.1111/j.1365-2265.2007.02998.x)

45 van den Beld AW, Bots ML, Janssen JA, Pols HA, Lamberts SW \& Grobbee DE. Endogenous hormones and carotid atherosclerosis in elderly men. American Journal of Epidemiology 2003157 25-31. (https://doi.org/10.1093/aje/kwf160)

46 Kawachi S, Takeda N, Sasaki A, Kokubo Y, Takami K, Sarui H, Hayashi M, Yamakita N \& Yasuda K. Circulating insulin-like growth factor-1 and insulin-like growth factor binding protein-3 are associated with early carotid atherosclerosis. Arteriosclerosis, Thrombosis, and Vascular Biology 200525 617-621. (https://doi. org/10.1161/01.ATV.0000154486.03017.35)

47 van Bunderen CC, van Nieuwpoort IC, van Schoor NM, Deeg DJ, Lips P $\&$ Drent ML. The association of serum insulin-like growth factor-I with mortality, cardiovascular disease, and cancer in the elderly: a population-based study. Journal of Clinical Endocrinology and Metabolism 201095 4616-4624. (https://doi.org/10.1210/jc.2010-0940)

48 Sanders JL, Guo W, O'Meara ES, Kaplan RC, Pollak MN, Bartz TM, Newman AB, Fried LP \& Cappola AR. Trajectories of IGF-I predict mortality in older adults: the cardiovascular health study. Journals of Gerontology 201873 953-959. (https://doi.org/10.1093/gerona/glx143)

49 Thum T, Hoeber S, Froese S, Klink I, Stichtenoth DO, Galuppo P, Jakob M, Tsikas D, Anker SD, Poole-Wilson PA et al. Age-dependent impairment of endothelial progenitor cells is corrected by growthhormone-mediated increase of insulin-like growth-factor-1. Circulation Research 2007100 434-443. (https://doi.org/10.1161/01. RES.0000257912.78915.af)

50 Khan AS, Sane DC, Wannenburg T \& Sonntag WE. Growth hormone, insulin-like growth factor-1 and the aging cardiovascular system. Cardiovascular Research 200254 25-35. (https://doi.org/10.1016/ s0008-6363(01)00533-8)
51 Schmidt-Lucke C, Rossig L, Fichtlscherer S, Vasa M, Britten M, Kamper U, Dimmeler S \& Zeiher AM. Reduced number of circulating endothelial progenitor cells predicts future cardiovascular events: proof of concept for the clinical importance of endogenous vascular repair. Circulation 2005111 2981-2987. (https://doi.org/10.1161/ CIRCULATIONAHA.104.504340)

52 Fadini GP, Dassie F, Albiero M, Boscaro E, Albano I, Martini C, de Kreutzenberg SV, Agostini C, Avogaro A, Vettor R et al. Endothelial progenitor cells are reduced in acromegalic patients and can be restored by treatment with somatostatin analogs. Journal of Clinical Endocrinology and Metabolism 201499 E2549-E2556. (https://doi. org/10.1210/jc.2014-2275)

53 Lombardi G, Galdiero M, Auriemma RS, Pivonello R \& Colao A. Acromegaly and the cardiovascular system. Neuroendocrinology 2006 83 211-217. (https://doi.org/10.1159/000095530)

54 Isgaard J, Arcopinto M, Karason K \& Cittadini A. GH and the cardiovascular system: an update on a topic at heart. Endocrine 2015 48 25-35. (https://doi.org/10.1007/s12020-014-0327-6)

55 Troncoso R, Ibarra C, Vicencio JM, Jaimovich E \& Lavandero S. New insights into IGF-1 signaling in the heart. Trends in Endocrinology and Metabolism 201425 128-137. (https://doi.org/10.1016/j. tem.2013.12.002)

56 Verdecchia P, Reboldi G, Schillaci G, Borgioni C, Ciucci A, Telera MP, Santeusanio F, Porcellati C \& Brunetti P. Circulating insulin and insulin growth factor-1 are independent determinants of left ventricular mass and geometry in essential hypertension. Circulation 1999100 1802-1807. (https://doi.org/10.1161/01.cir.100.17.1802)

57 Verhelst J, Velkeniers B, Maiter D, Haentjens P, T'Sjoen G, Rietzschel E, Corvilain B, Abrams P, Nobels F, Abs R et al. Active acromegaly is associated with decreased hs-CRP and NT-proBNP serum levels: insights from the Belgian registry of acromegaly. European Journal of Endocrinology 2013168 177-184. (https://doi. org/10.1530/EJE-12-0753)

58 Koegelenberg AS, Smith W, Schutte R \& Schutte AE. IGF-1 and NT-proBNP in a black and white population: the SABPA study. European Journal of Clinical Investigation 201646 795-803. (https:// doi.org/10.1111/eci.12663)

59 Krim SR, Vivo RP, Krim NR, Qian F, Cox M, Ventura H, Hernandez AF, Bhatt DL \& Fonarow GC. Racial/Ethnic differences in B-type natriuretic peptide levels and their association with care and outcomes among patients hospitalized with heart failure: findings from get with the guidelines-heart failure. JACC: Heart Failure $2013 \mathbf{1}$ 345-352. (https://doi.org/10.1016/j.jchf.2013.04.008)

60 Motiwala SR, Sarma A, Januzzi JL \& O’Donoghue ML. Biomarkers in ACS and heart failure: should men and women be interpreted differently? Clinical Chemistry $20146035-43$. (https://doi. org/10.1373/clinchem.2013.202531)

61 Wang TJ, Larson MG, Levy D, Leip EP, Benjamin EJ, Wilson PW, Sutherland P, Omland T \& Vasan RS. Impact of age and sex on plasma natriuretic peptide levels in healthy adults. American Journal of Cardiology 200290 254-258. (https://doi.org/10.1016/s00029149(02)02464-5)

Received 2 July 2019

Revised version received 29 October 2019

Accepted 7 November 2019 